\title{
Enabling Oral Cancer Translational Research in India
}

\section{Prakash S Bisen*}

Professor, Emeritus Scientist, Defence Research and Development Establishment (DRDE), Ministry of Defence, India

Oral cancer is a major health problem in India. Survival rate has not improved over past couple of decades in spite of our understanding of tumorigenesis at molecular level. High mortality due to oral cancer in India can be attributed to various factors like genetic vulnerability, widespread use of tobacco, environment, and life-style. Genetic polymorphism among patient population, evolving heterogeneity among cancer sub-types, lack of prefect disease model are some of the concomitant factors which makes management of oral cancer very challenging task. Most of the drugs fail later during clinical trials; even after carefully designed trials backed by encouraging preclinical results. Such late stage failures are mostly due to absence of animal model which can perfectly simulate human physiology. There exist wide gap between basic researcher and clinical researcher, who more than often work in silos. All these factors contribute towards translational lag between fruition of discoveries from basic research into clinical use. Drug discovery and development cost is yet another deterring factor for developing countries like India.

Translational research in oral cancer is highly desired to come up with better diagnostics and therapeutic applications to improve such dismal picture created high frequency of deaths by oral cancer. Success of the translational research will depend on close co-operation between clinical researcher and bench scientist. Such co-operation will enable discovery or validation of targets among ethnic population. Clinical researcher can help in sensitizing bench scientist to develop patient centric therapies, by making them aware of practical issues which are not encountered in animal studies. Such close cooperation would also enable refinement of theoretical disease models by including significant parameters from clinical observations and these models can be used to disease diagnosis, target discovery, safety and efficacy evaluation. Utilizing such theoretical models will help in optimizing effort, time and cost involved in different phases of drug discovery. Natural compounds with medicinal values are used in India from time innumerable. Translational research focused on use of active compounds from these natural sources should be attempted to design therapeutic interventions for potential targets present in ethnic community. Our group is involved in translational research with an objective to design therapeutic and diagnostic application for oral cancer focused on validated targets like survivin [1-4], Cox-2 [5] and evaluating therapeutic potential of natural anti-cancer compounds [68]. Information exchange and sharing is integral part of translational research, which is enabled by open access journal like JCST.

Translational research will also require large scale collaboration among vibrant scientific community working towards common objective of reducing mortality, incidence rate for oral cancer. Strong policy level commitment from Indian government in the form of rationalizing tobacco use, promoting translational research, spreading community awareness will go long way in saving millions of lives on stake due to oral cancer.

\section{References}

1. Khan Z, Khan N, Varma AK, Tiwari RP, Mouhamad S, et al. (2010) Oxaliplatinmediated inhibition of survivin increases sensitivity of head and neck squamous cell carcinoma cell lines to paclitaxel. Curr Cancer Drug Targets 10: 660-669.
2. Khan Z, Khan N, Tiwari RP, Patro IK, Prasad GB, et al. (2010) Down-regulation of survivin by oxaliplatin diminishes radioresistance of head and neck squamous carcinoma cells. Radiother Oncol 96: 267-273.

3. Khan Z, Tiwari RP, Mulherkar R, Sah NK, Prasad GB, et al. (2009) Detection of survivin and p53 in human oral cancer: correlation with clinicopathologic findings. Head Neck 31: 1039-1048.

4. Sah NK, Khan Z, Khan GJ, Bisen PS (2006) Structural, functional and therapeutic biology of survivin. Cancer Lett 244: 164-171.

5. Khan Z, Khan N, Tiwari RP, Sah NK, Prasad GB, et al. (2011 Biology of Cox-2 an application in cancer therapeutics. Curr Drug Targets 12: 1082-1093.

6. Bisen PS, Baghel RK, Sanodiya BS, Thakur GS, Prasad GB (2010) Lentinus edodes: a macrofungus with pharmacological activities. Curr Med Chem 17 2419-2130.

7. Sanodiya BS, Thakur GS, Baghel RK, Prasad GB, Bisen PS (2009) Ganoderma lucidum: a potent pharmacological macrofungus. Curr Pharm Biotechnol 10: 717-742.

8. Thakur GS, Bag M, Sanodiya BS, Bhadouriya P, Debnath M, et al. (2009) Momordica balsamina: a medicinal and neutraceutical plant for health care management. Curr Pharm Biotechnol 10: 667-682.

*Corresponding author: Professor P.S. Bisen, Emeritus Scientist, Defence Research Development Establishment, Defence Research Development Organisation, Ministry of Defence, Govt. of India, Jhansi Road, GWALIOR 474002, India, E-mail: psbisen@gmail.com

Received December 16, 2011; Accepted December 30, 2011; Published January 02, 2012

Citation: Bisen PS (2012) Enabling Oral Cancer Translational Research in India. J Cancer Sci Ther 4: i-i. doi:10.4172/1948-5956.1000e103

Copyright: ( 2012 Bisen PS. This is an open-access article distributed under the terms of the Creative Commons Attribution License, which permits unrestricted use, distribution, and reproduction in any medium, provided the original author and source are credited. 